\title{
Bacterial Sepsis Secondary to Red Blood Cells Transfusion Despite Routine Platelet Culture Screening: A Case Report
}

\section{César Cerdas-Quesada*}

Especialidad de Inmunohematología y Banco de Sangre, Sistema de Estudios de Posgrado, Universidad de Costa Rica. San José, Costa Rica

\section{Background}

Bacterial contamination of hemocomponents is a leading cause of transfusion related fatality. Culturing components may detect the presence of bacteria, thus reducing the risk of a septic result alter transfusion. Bacteria that contaminate blood products may originate from donor skin flora, from donor asymptomatic bacteremia or from contamination during blood processing.

\section{Case Report}

A 35-year-old female developed fever and hypotension alter receiving a 25-day-old red blood cells (RBC) Group O, D- unit. Cultures from the RBC unit were positive for the presence of Staphylococcus capitis and, the platelets culture was negative to date in aerobic bottle. No abnormalities were identified on review of Collection and processing records.

\section{Conclusion}

Skin bacteria were implicated in an adverse RBC transfusion reaction and current screening methods for PLTs are not sufficient to detect all bacterial contamination. The routine use of an anaerobic culture bottle in addition to an aerobic bottle to both increase the sensitivity of detection and capture potentially clinicaly significant organisms. Donor skin desinfection methods are not simple and, multiple factors are envolved in the efficacy of the procedure.

\section{Description of Case Report}

A 35-year-old female developed fever and hypotension after receiving 25-day-old red blood cells (RBC) Group O, D- unit. The reaction began 15 minutes after the unit was started. The transfusion was given for transvaginal bleeding after postpartum because hemoglobine was $5.8 \mathrm{~g}$ per dL. Dyspnea, increasing fever (36.2$38.3^{\circ} \mathrm{C}$ ) occurred. Posttranfusion pulse rate was 79 per minutes and blood pressure was $113 / 63$. Sepsis was suspected and the transfusion was stopped immediately and the open port was campled the blood component bag placed in a sealed plastic bag to contain leakage, to decrease the risk of posttransfusion contamination and transfusion reaction evaluation was initiated. Our service has a standard operating procedure for performing an evaluation of a product implicated in a transfusion reaction. The bag was inspected to detect any visible anomaly. Blood cultures were not obtained from the patient before administering antibiotic therapy. Platelet unit was not transfused but one more RBC unit was transfused later without any event.

The blood bank was notified immediately because co components from the same donation may also be contaminated. The co component (fresh frozen plasma) was placed in quarantine pending further information. The residual volumen of the RBC unit was cultured into a set of aerobic and anaerobic culture bottles (BacT/ALERT, bioMerieux).

After treatment with broad-spectrum antibiotics, she was eventually discharged from the hospital.
Laboratory workup revealed no evidence of hemolysis. Gram stain of the residual component showed gram-positive cocci. Cultures of the unit grew Staphylococcus capitis within a few hours of aerobic and anaerobic bottles inoculations. A second sample is drawn and inoculated into a new aerobic bottle for confirmatory culture. Both inicial and confirmatory positive culture bottles were sent for bacterial isolation and identification with an automatic testing system (VITEK, bioMérieux, Durham, NC).

The donor was a 35-year-old man Group O, D- who met all donor suitability critera. At the time of donation, he indicated that he felt well denied chronic or other systemic diseases. Predonation temperature was $36.7^{\circ} \mathrm{C}$, blood pressure was $122 / 78$ and hemoglobine was $15.8 \mathrm{~g}$ per dL (Hemocue).

A review of collection and processing records revealed an uneventful donation procedure without evidence of technical abnormalities. The skin preparation was first scrubbeb thoughly with $10 \%$ povidoneiodine for 30 seconds. Any excess was then removed by sterile swabs. A $70 \%$ alcohol swab was then applied in a concentric and spiral manner for another 30 seconds. Alcohol was allowed to evaporate completely before venipuncture [1] there was no difficulty obtaining venous access, and repeated venipunctures were not performed. The platelets (PLT) concentrate unit from the same donor were cultured previously (5-day-old) using BacT/ALERT aerobic (BPA) blood culture bottle (BacT/ALERT, bioMerieux) as previously described. In brief, a sample is obtained from each pool (5 units) 18 to 24 hours alter whole blood collection, inoculated into a BPA, and incubated on the instrument for 7 days. The volume of pool sample was $10 \mathrm{~mL}$. The culture was negative to date.

The blood bank informed the final results of the invetigation such as cultures, isolate identification, and other laboratory results.

\section{Discussion}

Transfusion-associated bacterial sepsis due to contaminated platelets (PLT) is one of the most serious complications of transfusion and a leading cause of transfusion-associated morbility and mortality [2]. The risk of receiving bacterial contaminated products is estimated to be 50 to 250 times higher than the combined risk per unit of transfusion-related infection with human immunodeficiency virus I

*Corresponding author: César Cerdas-Quesada, Especialidad de Inmunohematología y Banco de Sangre, Sistema de Estudios de Posgrado, Universidad de Costa Rica. San José, Costa Rica, E-mail: cesar.cerdasquesada@ucr.ac.c

Received May 17, 2012; Accepted September 27, 2012; Published September 29,2012

Citation: Cerdas-Quesada C (2012) Bacterial Sepsis Secondary to Red Blood Cells Transfusion Despite Routine Platelet Culture Screening: A Case Report. J Blood Disorders Transf 3:130. doi:10.4172/2155-9864.1000130

Copyright: (c) 2012 Cerdas-Quesada C. This is an open-access article distributed under the terms of the Creative Commons Attribution License, which permits unrestricted use, distribution, and reproduction in any medium, provided the original author and source are credited. 
and II, hepatitis C virus, hepatitis B virus, and, human T-lymphotropic virus-I and - II [3].

Bacteria that contaminate blood products may originate from donor skin flora, from donor asymptomatic bacteremia or from contamination during blood processing [4]. Since the adoption of preventive measures, transfusion-related septic reactions are relatively rare, occurring at a frequency of less than 1 in 15,000 to 1 in 100,000 transfusions. The vast majority of septic transfusion reactions become symptomatic during the transfusion or within 4 hours afterward and, the majority of positive cultures are normal skin flora (e.g., Staphylococcus spp., Streptococcus spp.) suggesting contamination at the time of phlebotomy $[5,6]$.

The estimated risk of bacterial septic reaction alter transfusion is approximately 10-fold higher for each unit of PLTs compared with each unit of RBC [2-7]. Each year, nearly 14 million RBC units are transfused in the United States, of which an estimated 1 in 31,000 to less than 1 per 1 million RBC units may be bacterially contaminated and the reports suggest that bacterial contamination in $\mathrm{RBC}$ units is a concern and that unrecognized cases, underreporting, and regional variation may account for observed differences in incidence. Bacteria found in transfusion-associated sepsis with RBC units have envolved psychrophiles, which are capable of growth at temperatures of $1-4^{\circ} \mathrm{C}$ for up to 42 days and have been found to proliferate at low temperatures to more than $105 \mathrm{CFUs}$ per $\mathrm{Ml}$ [8]. Only approximately 17 percent of transfused contaminated products give rise to a reported septic transfusion reaction due to failure of the patient to react (in neutropenic patients or that already on antibiotic therapy), failure to recognize septic reactions, and/or failure to report those reactions that are recognized to the transfusion service [9].

Here has been reported a septic reaction with culture-tested platelets probably due to false-negative results associated with bacterial detection in single-bottle culture system. Transfusion of a bacterially contaminated unit frequently does not result in a clinically significant transfusion reaction. Bacterial load, growth kinetics, pathogenicity, and recipient characteristics can all affect the clinical consequences of transfusion of a contaminated unit [10]. The PLTs samples for culture were taken 5-day-old alter component production and were issued as negative to date and could be transfused. In general, units contaminated with a high bacterial load of rapidly growing organisms are both more likely to cause septic reactions and more likely to have a positive culture soon alter inoculation and be removed from inventory before transfusion [10]. In this experience the product was transfused and the PLTs culture did not become positive (aerobic culture) and, adverse reaction was observed. The patient did not receive concomitant antibiotic therapy, which can inhibit the growth of bacteria in blood cultures. Continuing reports of septic reactions alter transfusion of cultured-tested PLTs, and frequent single-bottle-positive results when testing with two-bottle system, suggest appreciable levels of false negative results with a commercially available bacterial detection system and the time to reactivity was accelerated in a BPN bottle compared to a BPA bottle (Bact/ALERT) $[11,12]$. RBC units may be sample 1 to 3 days after collection for optimal efficacy [8] and addition of anaerobic culture to our routine would significantly increase the detection rate of contamination as previously described [1].

Another issue is the donor desinfection methods that are not simple and multiple factors are envolved in the efficacy of the procedure and choosing the best method is dependent on these factors (disinfectant number, type, volume, concentration, or type of container, the decision to perform a single- or a double step disinfectation method, the application method, drying time, donors features and staff experience) [13].

\section{References}

1. Lee CK, Ho PL, Lee KY, Tsui GT, Chua E, et al. (2008) Value of anaerobic culture in bacterial surveillance program for platelet concentrates. Transfusion 48: $2606-2611$

2. Lin CY, Tseng SB, Lu PL, Chen TC, Lin WR, et al. (2011) Isolation of Streptococcus bovis from Apheresis platelets of asymptomatic donor warranted colonoscopy investigation: case report and literature review. Transfusion 51: 2023-2027.

3. Cunha G, Leao L, Pimenta F (2008) Bacterial contamination of random-donor platelets in a university hospital in the midwestern region of Brazil. Transfusion 48: $282-285$

4. Lessa F, Leparc GF, Benson K, Sanderson R, Van Beneden CA et al. (2008) Fatal Group C streptococcal infection due to transfusion of a bacterially contaminated pooled platelet unit despite routine bacterial culture screening Transfusion 48: 2177-2183

5. Eder AF, Goldman M (2011) How do I investigate septic transfusion reactions and blood donors with culture-positive platelet donations? Transfusion 51 1662-1668.

6. Eder AF, Kennedy JM, Dy BA, Notari EP, Skeate R, et al. (2009) Limiting and detecting bacterial contamination of Apheresis platelets: inlet-line diversion and increased culture volumen improve component safety. Transfusion 49: 15541563.

7. Blajchman MA (2002) Incidence and significance of the bacterial contamination of blood components. Dev Biol (Basel) 108: 59-67.

8. Chen CL, Yu JC, Holme S, Jacobs MR, Yomtovian R, et al. (2008) Detection of bacteria in stored red cell products using a culture-based bacterial detection system. Transfusion 48: 1550-1557.

9. Yomtovian RA, Palavecino EL, Dysktra AH, Downes KA, Morrissey AM, et al. (2006) Evolution of surveillance methods for detection of bacterial contamination of platelets in a university hospital, 1991 through 2004. Transfusion 46: 719730

10. Robillard P, Delage G, Itaj NK, Goldman M (2011) Use of hemovigilance data to evaluate the effectiveness of diversión and bacterial detection. Transfusion 51: $1405-1411$

11. Benjamin RJ, Wagner SJ (2007) The residual risk of sepsis: modeling the effect of concentration on bacterial detection in two-bottle culture Systems and an estimation of false-negative culture rates. Transfusion 47: 1381-1389.

12. Brecher ME, Hay SN (2007) Investigation of an isolate of Staphylococcus lugdunensis implicated in a platelet fatality: a possible advantage of the use of an anaerobic bottle. Transfusion 47: 1390-1394.

13. Bueno JL (2010) Skin disinfection and bacterial contamination of blood components: be simple. Transfusion 50: 5-8. 